\title{
Immunoreactivity of PAX 6, Recoverin and Calbindin Activity in the Retina of Buffaloes with Ageing
}

\author{
Prasanth Babu $\mathrm{A}^{\mathbf{1}^{*}}$, Jagapathi Ramayya $\mathrm{P}^{2}$, Nagamalleswari $\mathrm{Y}^{3}$, Sreenu $\mathrm{M}^{3}$ and Lakshmi Kavitha $\mathrm{K}^{3}$ \\ ${ }^{1}$ Department of Veterinary Anatomy, College of Veterinary Science, SVVU, Proddatur, Andhra Pradesh, INDIA \\ ${ }^{2}$ Department of Veterinary Anatomy, College of Veterinary Science, SVVU, Tirupati, Andhra Pradesh, INDIA \\ ${ }^{3}$ NTR College of Veterinary Science, SVVU, Gannavaram, Andhra Pradesh, INDIA \\ "Corresponding author: P Babu A; E-mail: prasanthankem@gmail.com
}

Received: 7 Aug., 2020

Revised: 01 Nov., 2020

Accepted: 21 Nov., 2020

\begin{abstract}
The present study was conducted in retina of 15 buffaloes and samples were categorized into group I (1-5 yrs), group II (6-10 yrs) and group III (10 yrs above). Immunopositive reaction for Pax6 in retinal pigment epithelium was strong in group I, mild to moderate reaction in group II buffaloes and no reaction in group III buffaloes. Strong immunopositive reaction against recover in was noticed in rods and cones, their nuclei of outer nuclear layer and binucleate cells of inner nuclear layer in group I and II buffaloes. Whereas moderate reaction was observed in the similar cells of retina in group III buffaloes. Strong Immunopositive reaction against calbindin was observed in the horizontal and amacrine cells of retina in group I and group II buffaloes and moderate reaction was observed in group III buffaloes.
\end{abstract}

\section{HIGHLIGHTS}

(0 PAX6 reaction in retinal pigment epithelium was decreased with advancement of age.

(0 Immunoreaction of recoverin in rod and cone cells was gradually decreased with advancement of age.

( Calbindin activity in horizontall and amacrine cells of inner nuclear layer of retina was decreased in old animals.

Keywords: PAX6, Recoverin, Calbindin, Immunoreactivity, Retina, Buffaloes

Once the optic cup has formed, RPE progenitors begin to accumulate melanin. During the initiation of the pigmentation program, the expression of PAX6 was detected throughout the RPE layer. In later stages, the expression of PAX6 was gradually reduced, first in the central and subsequently in the peripheral optic cup. PAX6 was eventually maintained in the pigmented cells of the ciliary body and iris also (Raviv et al., 2014).

Recoverin is a $23-\mathrm{kD} \mathrm{Ca}^{2+}$ - binding protein present in certain retinal neurons: rods, cones, bipolar cells and ganglion cells (Katamay and Nussenblatt, 2013). In darkness, $\mathrm{Ca}^{2+}$ enters the outer segment of rods through cGMP-gated channels and is extruded by an electrogenic exchanger which couples the movement of $4 \mathrm{Na}^{+}$and $1 \mathrm{~K}^{+}$ down their electrochemical gradients to the removal of 1 $\mathrm{Ca}^{2+}$. In the presence of light, fewer cGMP-gated channels are open, reducing $\mathrm{Ca}^{2+}$ influx in the face of continued $\mathrm{Ca}^{2+}$ extrusion; this results in a fall in the intracellular $\mathrm{Ca}^{2+}$ concentration. The lowered $\mathrm{Ca}^{2+}$ is thought to affect three aspects of the transduction machinery: (a) it decreases light dependent cGMP phosphodiesterase (PDE) activity, (b) it increases the channel's sensitivity for cGMP, and (c) it increases the activity of guanylate cyclases. Since the cell's responses to light reflect the contributions of all of these control mechanisms. $\mathrm{Ca}^{2+}$ - recoverin complex inhibits phosphorylation of rhodopsin by binding to rhodopsin kinase. Consistent with such an effect, dialysis

How to cite this article: Babu, P.A., Ramayya, J.P., Nagamalleswari, Y., Sreenu, M. and Kavitha, L.K. (2020). Immunoreactivity of PAX 6 , Recoverin and Calbindin activity in the retina of buffaloes with ageing. $J$. Anim. Res., 10(6): 949-952.

Source of Support: None; Conflict of Interest: None 
of exogenous $\mathrm{Ca}^{2+}$ - recoverin into isolated, intact rod outer segments delayed the recovery of the flash response and increases the rod's sensitivity to dim steady light (Zang and Neuhauss, 2018).

In retina immunoreactivity of calbindin was present in horizontal cells and amacrin]e cells in the outer plexiform layer (OPL) and do not appear in bipolar cells. At the inner margin of the INL and in the ganglion cell layer (GCL) show variable expression of calbindin (Haverkamp and Wassle, 2000). In Monkey, pig and sheep the calbindin reaction was stronger in the cones around the fovea, and became progressively completely negative into the fovea. Rods were calbindin-negative. Horizontal cells, some bipolar cells and amacrine cells were showed strong reaction for calbindin. In Pig and sheep few ganglion cells and their axons were reacted for calbindin (Pasteels et al., 1990).

\section{MATERIALS AND METHODS}

The present study was conducted on 15 eye balls collected from 15 buffaloes from the slaughter houses around Proddatur. The age of the buffaloes were estimated by dentition (Saini et al., 1982). These buffaloes were categorized into 3 groups based on their age mentioned as group I: 1-5 yrs, group II: 6-10 yrs and group III: 10 yrs above. Then five tissue samples from each age group were processed for paraffin sections. Paraffin sections of retina samples were cut at $3-4 \mu \mathrm{m}$ thickness taken on APES (Amino Propyl tri Ethoxy Silane) coated slides and incubated overnight at $37^{\circ} \mathrm{C}$. These slides were subjected to immunohistochemistry protocol as mentioned below. Sections were deparaffinised by using xylene two changes for 15 minutes each and dipped in absolute alcohol two changes to remove xylene. Washed under running tap water for $10 \mathrm{~min}$, rinsed in distilled water for $5 \mathrm{~min}$. Kept in Tris EDTA buffer (pH-9.0) and hot water bath treatment was given for $20 \mathrm{~min}$ at $100^{\circ} \mathrm{C}$ to retrieve the antigenic sites. Cooled to the room temperature by kept in the distilled water for $5 \mathrm{~min}$ and in Tris buffer saline for 5 min. The slides were kept in the humid chamber and in the peroxidase block solution (3\% hydrogen peroxidase - freshly prepared) for 30 min to block the endogenous peroxidises, washed in Tris buffer saline for 3 times 5 min each. The power block solution using 1.5\% BSA was poured on tissue section and kept for 30 min. Primary
antibodies(PAX 6, Recoverin, Calbindin) were added on the sections and slides were kept at room temperature for $2 \mathrm{hrs}$ or overnight at $4^{\circ} \mathrm{C}$, washed in Tris buffer saline for 5 min each in 3 changes. Secondary antibody, anti species antibody with HRP was added and kept for 1 hour, washed in Tris buffer saline for 5 minutes each in 3 changes. Using 2, 2 Dichloro Diaminobenzidine (DAB), the working colouring reagent was prepared by adding one drop of DAB to $1 \mathrm{ml}$ of substrate. The sections were kept in the colouring reagent for $30 \mathrm{~min}$ and washed in Tris buffer saline for 2 times and in tap water for $10 \mathrm{~min}$. Stained with Harris Haematoxylin for 1 minute and washed in tap water for $5 \mathrm{~min}$. Then air dried and mounted with DPX.

\section{RESULTS AND DISCUSSION}

\section{PAX6 (Paired box protein 6)}

Immunopositive reaction against Pax6 in retinal pigment epithelium was strong in group I, mild to moderate reaction in group II buffaloes and nil reaction in group III buffaloes (Fig. 1).

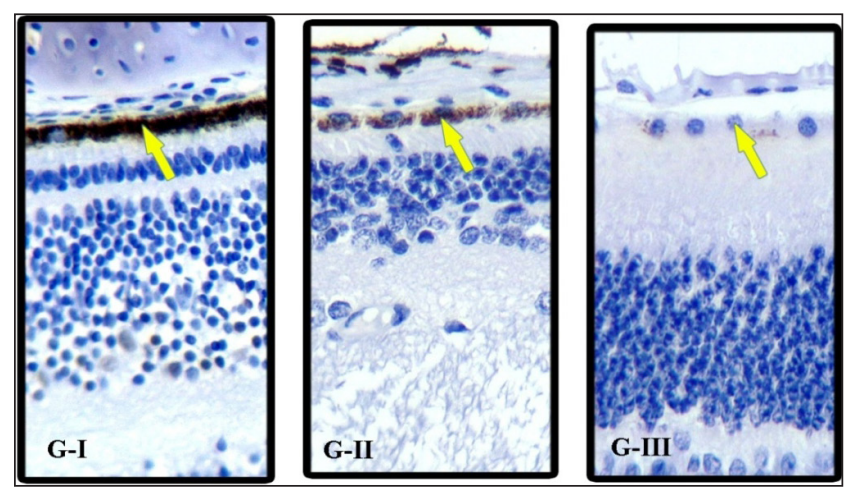

Fig. 1: Photomicrograph of retinal pigment epithelium of retina of group I (G-I) buffaloes showing strong, group II (GII) buffaloes showing mild to moderate and group III (G-III) buffaloes showing nil immunopositive reaction (Arrow) for anti PAX6. X400

It was concluded that pigment biogenesis in RPE and activity of retinal pigment epithelium was decreased from group I to III buffaloes. Similarly, Raviv et al. (2014) reported that once the optic cup has formed in humans, RPE progenitors begin to accumulate melanin. During the initiation of the pigmentation program, the expression of PAX6 was detected throughout the RPE layer. In later 
stages, the expression of PAX6 was gradually reduced, first in the central and subsequently in the peripheral optic cup. PAX6 was eventually maintained in the pigmented cells of the ciliary body and iris also.

\section{Recoverin}

In the present study strong immunopositive reaction against recoverin was noticed in rods and cones, their nuclei of outer nuclear layer and binucleate cells of inner nuclear layer in group I and II buffaloes. Whereas moderate reaction was observed in the similar cells of retina in group III buffaloes (Fig. 2). Hence, it was concluded that activity of photoreceptors and their nuclei and binucleate cells of bovine retina was increased in middle age, but gradually decreased in old animals. These results indicated that the $\mathrm{Ca}^{2+}$ dependent recoverin / rhodopsin kinase interaction and recoverin on rhodopsin phosphorylation in photoreceptor light adaptation was more in young and adult age than old age of buffaloes (Fig. 2). Katamay and Nussenblatt (2013) reported that the specific and $\mathrm{Ca}^{2+}$ dependent recoverin / rhodopsin kinase interaction was necessary for the inhibitory effect of recoverin on rhodopsin phosphorylation and may play an important role in photoreceptor light adaptation and it was greater in younger than aged persons. Further, they also reported that the $\mathrm{Ca}^{2+}$ binding protein recoverin may regulate visual transduction in retinal rods and cones and prolongs the dark-adapted flash response and increases the rod's sensitivity to dim steady light.
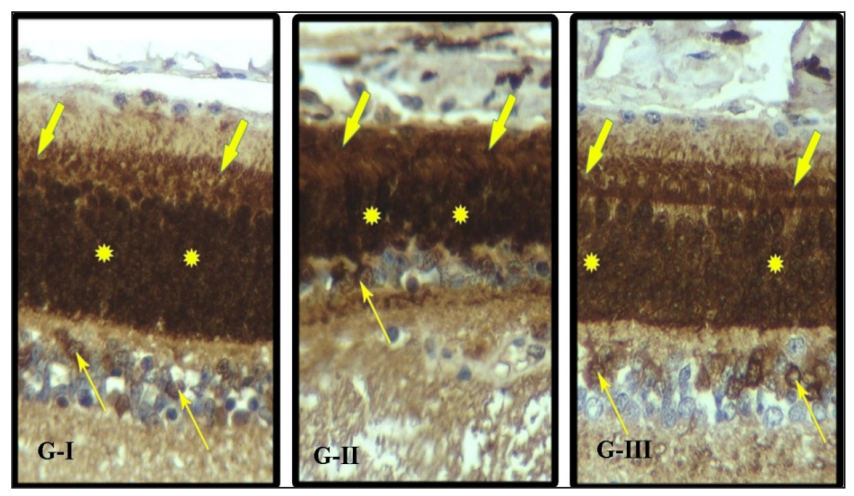

Fig. 2: Photomicrograph of retina of group I (G-I) and group II (G-II) buffaloes showing strong and group III (G-III) buffaloes showing moderate immunopositive reaction in rod and cone cells (Large Arrow), their nuclei (Star) and Binucleate cells (Small Arrow) for anti recoverin antibody X400

\section{Calbindin}

Strong Immunopositive reaction against calbindin was observed in the horizontal and amacrine cells of retina in group I and group II buffaloes and moderate reaction was observed in group III buffaloes. Hence, it was concluded that intramembranous transport of calcium or intracellualr calcium buffer in retinal neuronal cells activity of horizontal and amacrine cells bovine retina was not changed from early to old age buffaloes (Fig. 3). Similar observations were also noted by Pasteels et al. (1990) in monkey, pig and sheep and Haverkamp and Wassle (2000) in mouse as reported in the present study.

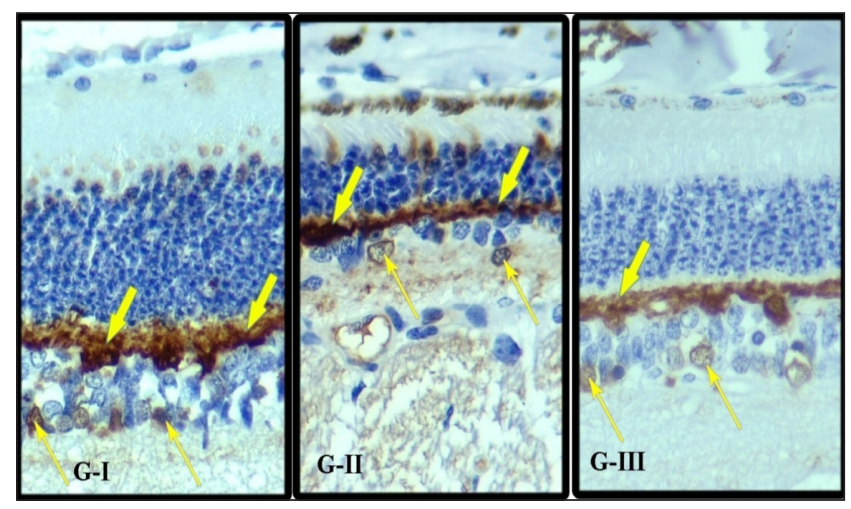

Fig. 3: Photomicrograph of retina of group I(G-I), group II(GII), buffaloes showing strong and group III(G-III) buffaloes showing moderate immunopositive reaction for anti calbindin antibody in horizontal cells (Thick arrow) and amacrine cells (Thin arrow). X400

\section{CONCLUSION}

It was concluded that pigment biogenesis in RPE and activity of retinal pigment epithelium was decreased from group I to III buffaloes with an Immunohistological study of anti PAX6 antibody studies. An Immunohistological study of anti recoverin antibody studies concluded that the $\mathrm{Ca}^{2+}$ dependent recoverin / rhodopsin kinase interaction and recoverin on rhodopsin phosphorylation in photoreceptor light adaptation was more in young and adult age than old age of buffaloes. An Immunohistological study of antirecoverin antibody studies concluded that intra membranous transport of calcium or intracellualr calcium buffer in retinal neuronal cells activity of horizontal and amacrine cells of bovine retina was not changed from early to old age buffaloes. 


\section{REFERENCES}

Haverkamp, S. and Wassle, H. 2000. Immunocytochemical analysis of the mouse retina. J. Comp. Neurol., 424: 1-23.

Katamay, R. and Nussenblatt, R.B. 2013. Blood-Retinal Barrier, Immune Privilege, and Autoimmunity. Retina, 5(1): 579-589

Pasteels, B., Rogers, J., Blachier, F. and Pochet, R. 1990. Calbindin and calretinin localization in retina from different species. Vis. Neurosci., 5: 1-16.

Raviv, S., Bharti, K., Rencus-Lazar, S., Cohen-Tayar, Y., Schyr, R., Evantal, N., Meshorer, E., Zilberberg, A., Idelson, M., Reubinoff, B., Grebe, R., Rosin-Arbesfeld, R., Lauderdale, J., Lutty, G., Arnheiter, H. and Ashery-Padan, R. 2014. PAX6 Regulates Melanogenesis in the Retinal Pigmented Epithelium through Feed-Forward Regulatory Interactions with MITF. PLoS. Genet., 10(5): 1-15.
Saini, A., Gill, R.S. and Gill, S.S. 1982. Dentition and ageing in Murrah buffaloes. Ind. J. Dairy. Sci., 35(3): 257-262.

Zang, J. and Neuhauss, S.C.F. 2018. The Binding Properties and Physiological Functions of Recoverin. Front. Mol. Neurosci., 11: $1-10$. 